\title{
ANALISIS HUBUNGAN KONDISI FISIK RUMAH DENGAN KEJADIAN PENYAKIT TB PARU DI WILAYAH PUSKESMAS II AJIBARANG KABUPATEN BANYUMAS TAHUN 2016
}

\author{
Syahbani, ${ }^{1)}$ Lagiono, ${ }^{2)}$ Budi Triyantoro ${ }^{3)}$ \\ Jurusan Kesehatan Lingkungan, Politeknik Kesehatan Kemenkes Semarang, \\ Jl.Raya Baturaden KM 12 Purwokerto, Indonesia
}

\begin{abstract}
Abstrak
Jumlah suspek TB paru di Kabupaten Banyumas Tahun 2014 sebanyak 1.454 kasus dan terdiagnosis BTA + sebanyak 1.991 kasus yang lebih banyak dibandingkan jumlah suspek. Tujuan umum penelitian ini adalah untuk mengetahui hubungan kondisi fisik rumah (jenis lantai, luas ventilasi, pencahayaan alami, kepadatan hunain) terhadap kejadian penyakit TB Paru di wilayah Puskesmas II Ajibarang Tahun 2016. Jenis penelitian ini adalah penelitian observasional analitik dengan pendekatan case control study di wilayah Puskesmas II Ajibarang Kabupaten Banyumas Propinsi Jawa Tengah. Populasi penelitian mencakup semua penderita TB Paru yang ada di wilayah Puskesmas II Ajibarang, berjumlah 48 penderita pada tahun 2014 - 2015. Sampel dalam penelitian ini berjumlah 96 orang, terdiri dari kelompok kasus berjumlah 48 orang dan kelompok kontrol berjumlah 48 orang yang dihitung dengan teknik purposive sampling, Hasil penelitian menyatakan bahwa jenis lantai rumah sebagian besar kedap air yaitu 63 rumah (65,6\%), luas ventilasi memenuhi syarat yaitu 55 rumah (57,3\%), pencahayaan alami memenuhi syarat yaitu 75 rumah $(78,1 \%)$ dan kepadatan huniannya memenuhi syarat yaitu 76 rumah (79,2\%). Ada hubungan antara jenis lantai ( $p$ value $=0,018 ; O R=2,846)$, luas ventilasi $(p$ value $=0,023 ; O R=2,600)$, pencahayaan alami $(p$ value $=0,026 ; O R=3,182)$ dan kepadatan hunian ( $p$ value $=0,003 ; O R=5,500)$ dengan kejadian TB Paru di Wilayah Puskesmas II Ajibarang Tahun 2015. Kesimpulan dari penelitian ini adalah ada hubungan antara kepadatan hunian dengan kejadian TB Paru. Penelitian ini perlu dikembangkan lebih lanjut dengan meneliti faktor lain yang dapat mempengaruhi kejadian TB paru dari aspek perilaku keluarga penderita TB paru.
\end{abstract}

Kata Kunci : Fisik Rumah, TB Paru

\begin{abstract}
The number of suspected pulmonary TB in Banyumas 2014 and as many as 1,454 cases diagnosed $B T A+$ as many as 1,991 cases more than the number of suspect. The general objective of this research is to know. relationship physical condition (type of flooring, ventilation, natural lighting, residential density) with the incidence of pulmonary TB disease in the health center II Ajibarang 2016. This type of research is an analytic observational study with the approach of case control study in Puskesmas II Ajibarang Banyumas regency, Central Java Province. The study population includes all patients with pulmonary tuberculosis in Puskesmas II Ajibarang, totaling 48 patients in 2014 2015. The sample in this study amounted to 96 people, consisting of case group of 48 people and a control group of 48 people which is calculated by using purposive sampling, The study states that the type floor houses most watertight is 63 houses (65.6\%), ventilation qualify namely 55 houses (57.3\%), natural lighting qualify namely 75 houses (78.1\%) and density occupancy qualify namely 76 houses (79.2\%). There is a relationship between the type of flooring ( $p$ value $=0.018 ;$ OR $=2.846)$, ventilation $(p$ value $=0.023 ; O R=2.600)$, natural lighting $(p$ value $=0.026 ; O R=3.182)$ and population density ( $p$ value $=0.003 ; O R=5.500$ ) and the incidence of pulmonary TB in Puskesmas Region II Ajibarang 2016. The conclusion of this study is There is a relationship between residential density with the incidence of pulmonary TB. This study needs to be developed further to examine other factors that may affect the incidence of pulmonary tuberculosis on the behavioral aspects of pulmonary TB patients' family.
\end{abstract}

Keywords : Physical Houses, pulmonary tuberculosis

\footnotetext{
1) E-mail: syahbani_syah@yahoo.co.id

${ }^{2)}$ E-mail: lagiono abdulwahid@yahoo.co.id

3) E-mail: musthabira@yahoo.co.id
} 


\section{PENDAHULUAN}

TB. Paru merupakan penyakit menular langsung yang disebabkan oleh kuman Mycobacterium Tuberculose. Penyakit TB. Paru di Indonesia masih merupakan masalah utama kesehatan masyarakat. Pada kehidupan sehari-hari penyakit TB. Paru sering dikenal dengan sebutan penyakit TBC. Menurut laporan World Health Organization (WHO) bahwa Indonesia merupakan negara urutan ke4 dengan kasus TB paru terbanyak pada tahun 2010 setelah India, Cina, dan Afrika Selatan. Prevalensi kasus TB paru di Indonesia sebesar 244 per 100.000 dan insidensi untuk semua tipe TB paru adalah 228 per 100.000 . Insidensi kasus TB paru-BTA positif sebesar 102 per 100.000 dan angka kematian mencapai 39 kasus per 100.000 atau sekitar 250 orang per hari. Fakta tersebut didukung oleh kondisi lingkungan perumahan, dan sosial ekonomi masyarakat (WHO, 2010).

Angka penemuan kasus baru TB Paru di Provinsi Jawa Tengah Tahun 2013 baru mencapai 58,48\%. Angka kesembuhan (Cure Rate/CR) TB paru Provinsi Jawa Tengah tahun 2012 sebesar 82,90\% dibawah target nasional $(85 \%)$ dan lebih sedikit bila dibandingkan tahun 2011 (85,15\%) (Profil Kesehatan Provinsi Jawa Tengah, 2013). Jumlah suspek TB paru di Kabupaten Banyumas Tahun 2014 sebanyak 1.454 kasus dan terdiagnosis BTA + sebanyak 1.991 kasus yang lebih banyak dibandingkan jumlah suspek (Dinkes Kabupaten Banyumas, 2014).

Indonesia telah melaksanakan program penanggulangan TB.Paru melalui Balai pengobatan paru atau BP.Paru dan mulai tahun 1969 penanggulangan TB. Paru dilakukan secara nasional melalui puskesmaspuskesmas yang ada di seluruh Indonesia, tetapi upaya tersebut belum menunjukkan hasil yang optimal. Menurut Jhon Gordon dalam Annies (2006), bahwa kejadian sakit pada seseorang atau sekelompok masyarakat dipengaruhi oleh beberapa faktor, yaitu faktor Agent (penyebab penyakit), Host (pejamu) dan Environment (lingkungan).

Menurut Beaglehole (1997), faktor risiko yang dapat menimbulkan penyakit Tuberkulosis adalah faktor genetik, malnutrisi, vaksinasi, kemiskinan dan kepadatan penduduk. Tuberkulosis terutama banyak terjadi di populasi yang mengalami stress, nutrisi jelek, rumah penuh hunian, ventilasi yang tidak baik, perawatan yang tidak cukup dan perpindahan tempat. Genetik berperan kecil, dan dalam hal ini yang berperan terhadap besarnya insiden kejadian Tuberkulosisa dalah faktor-faktor lingkungan (Fletcher, 1992).

Data penderita TB.Paru di Puskesmas II Ajibarang tahun 2014 - 2015 berjumlah 48 penderita dan masih banyak kondisi fisik rumah di wilayah Puskesmas II Ajibarang yang belum memenuhi syarat kesehatan. Dari jumlah rumah di wilayah Puskesmas II Ajibarang sebanyak 9.741 rumah, yang memenuhi persyaratan kesehatan sebanyak 4.426 rumah dan sebanyak 5.315 rumah tidak memenuhi persyaratan. Berdasarkan data tersebut diatas, maka penulis terdorong untuk mengambil judul skripsi "Studi Hubungan Kondisi Fisik Rumah terhadap Kejadian Penyakit TB. Paru di wilayah Puskesmas II Ajibarang Kabupaten Banyumas Tahun 2016 “.

Penelitian ini bertujuan untuk mengetahui. hubungan kondisi fisik rumah terhadap kejadian penyakit TB Paru di wilayah Puskesmas II Ajibarang Tahun 2016.

\section{METODE PENELITIAN}

Jenis penelitian ini adalah penelitian observasional analitik dengan pendekatan case control study. Pelaksanaan penelitian dilaksanakan mulai Maret sampai dengan April 2016. Lokasi penelitian dilakukan di wilayah Puskesmas II Ajibarang Kabupaten Banyumas Propinsi Jawa Tengah. Populasi penelitian mencakup semua penderita TB. Paru yang ada di wilayah Puskesmas II Ajibarang, berjumlah 48 orang pada tahun 2014 - 2015. Sampel dalam penelitian ini berjumlah 96 orang, terdiri dari kelompok kasus berjumlah 48 orang dan kelompok kontrol berjumlah 48 orang, Pengambilan sampel kasus menggunakan teknik total sampling dan sampel kontrol diambil dengan teknik purposive sampling, yaitu yang rumahnya berdekatan dengan sampel kasus. Instrumen data dilakukan dengan menggunakan Questioner dan Checklist dengan menggunakan alat Lux meter, Roll meter dan Kalculator. Analisa univariat dilakukan dengan tujuan untuk mendeskripsikan tiap variabel, yang meliputi jenis lantai rumah, luas ventilasi rumah, 
pencahayaan alami rumah dan kepadatan hunian rumah penderita TB. Paru di wilayah Puskesmas II Ajibarang, Kabuapten Banyumas. Analisa bivariat menggunakan uji statistik $\mathrm{X}^{2}$ (Chi-square). Rasio Odds ini dilakukan dengan tujuan untuk menganalisis pengaruh hubungan jenis lantai rumah, luas ventilasi rumah, pencahayaan alami rumah dan kepadatan hunian rumah terhadap kejadian penyakit TB.

\section{HASIL PENELITIAN DAN PEMBAHASAN}

\section{A. Analisis Univariat}

1. Jenis lantai rumah responden

Jenis lantai rumah responden di wilayah Puskesmas II Ajibarang dapat dilihat pada tabel 1 di bawah ini:

Tabel. 1. Distribusi Frekuensi Kondisi Jenis Lantai Rumah

\begin{tabular}{clcc}
\hline No & Jenis lantai & $\begin{array}{c}\text { Frekuensi } \\
\text { (Orang) }\end{array}$ & $\begin{array}{c}\text { Persentase } \\
(\%)\end{array}$ \\
\hline 1. & $\begin{array}{l}\text { Tidak kedap } \\
\text { air }\end{array}$ & 33 & 34,4 \\
2. & Kedap air & 63 & 65,6 \\
\hline & Jumlah & 96 & 100,0 \\
\hline
\end{tabular}

Responden yang diteliti sebanyak 96 orang sebagian besar jenis lantai rumahnya kedap air, yaitu 63 rumah $(65,6 \%)$ dan yang tidak kedap yaitu 33 rumah $(34,4 \%)$.

Menurut Kepmenkes RI. No. 829 / Menkes/ SK / VII / 1999, menyatakan bahwa rumah yang tidak memenuhi persyaratan kesehatan (lantai rumah tidak kedap air) dapat menimbulkan penyakit, termasuk didalamnya adalah penyakit TB.Paru.

Lantai yang tidak memenuhi persyaratan kesehatan (lantai tidak kedap air) dapat dijadikan tempat hidup dan berkembangbiaknya kuman dan vektor penyakit, dan menyebabkan udara dalam ruangan menjadi lembab, serta pada musim panas dapat menyebabkan lantai menjadi kering, sehingga dapat menimbulkan debu yang berbahaya bagi penghuninya.

Rumah yang lantai rumahnya belum kedap air, hendaknya mendapatkan perhatian dari pihak pemerintah, khususnya dari Dinas Kesehatan untuk mengupayakan adanya bantuan. Keluarga juga perlu memprioritaskan untuk membuat lantai kedap air yang tidak perlu menggunakan keramik, tetapi cukup dengan semen. Jika belum dapat membuat lantai yang kedap air, keluarga sebaiknya menjaga agar sering menutup pintu agar debu di lantai tidak berterbangan.

\section{Luas ventilasi rumah responden}

Luas ventilasi rumah responden di wilayah Puskesmas II Ajibarang dapat dilihat pada tabel 2 di bawah ini:

Tabel. 2. Distribusi Frekuensi Kondisi Luas Ventilasi Rumah Responden

\begin{tabular}{clcc}
\hline No & $\begin{array}{c}\text { Luas } \\
\text { ventilasi }\end{array}$ & $\begin{array}{c}\text { Frekuensi } \\
(\text { Orang) }\end{array}$ & $\begin{array}{c}\text { Persentase } \\
(\%)\end{array}$ \\
\hline $1 . \quad \begin{array}{l}<10 \% \text { dari } \\
\text { luas lantai }\end{array}$ & 41 & 42,7 \\
$2 . \quad \begin{array}{l}\geq 0 \% \text { dari } \\
\text { luas lantai }\end{array}$ & 55 & 57,3 \\
\hline \multicolumn{2}{l}{ Jumlah } & 96 & 100,0 \\
\hline
\end{tabular}

Responden yang diteliti sebanyak 96 orang sebagian besar luas ventilasinya memenuhi syarat yaitu, 55 rumah $(57,3 \%)$ dan yang tidak memenuhi syarat yaitu 41 orang $(42,7 \%)$.

Luas ventilasi yang dimaksudkan dalam penelitian ini adalah luas ventilasi yang meliputi luas lubang angin dan luas jendela ruang tidur dibagi dengan luas lantai. Bila ukuran luas ventilasi dibagi luas lantai lebih kecil dari $10 \%$ dari luas lantai, dapat dikatakan bahwa luas ventilasi tersebut tidak memenuhi syarat kesehatan dan merupakan faktor risiko yang berhubungan dengan kejadian TB. Paru.

Menurut Kepmenkes RI. No. 829 / Menkes/ SK / VII / 1999, menyatakan bahwa rumah yang tidak memenuhi persyaratan kesehatan (luas ventilasi rumah $<10 \%$ dari luas lantai) dapat menimbulkan penyakit termasuk didalamnya adalah penyakit TB.Paru.

Ventilasi merupakan lubang angin yang berfungsi sebagai sirkulasi udara yang dapat memberikan kenyamanan bagi penghuni rumah serta dapat memberikan kontribusi terciptanya temperatur udara dan kelembaban udara yang memungkinkan suatu bibit penyakit akan 
berkembang biak atau mati. Aliran udara diusahakan Cross-ventilation dengan menempatkan lubang ventilasi berhadapan antara dua dinding ruangan (Djasio Sanropie,dkk, 1989).

Rumah yang sudah memiliki ventilasi dengan luas memenuhi syarat hendaknya membiasakan membuka dipagi hari dan menutupnya di sore hari agar udara dan sinar matahari dapat masuk ke dalam rumah. Adapun rumah yang luas ventilasinya belum memenuhi syarat hendaknya berusaha agar memperluas ventilasi yang memenuhi syarat..

\section{Pencahayaan alami rumah responden}

Pencahayaan alami rumah responden di wilayah Puskesmas II Ajibarang dapat dilihat pada tabel. 3 dibawah ini:

Tabel 3. Distribusi Frekuensi Kondisi Pencahayaan Alami Rumah

\begin{tabular}{cccc}
\hline No & $\begin{array}{c}\text { Pencahayaan } \\
\text { alami }\end{array}$ & $\begin{array}{c}\text { Frekuensi } \\
\text { (Orang) }\end{array}$ & $\begin{array}{c}\text { Persentase } \\
(\%)\end{array}$ \\
\hline 1. & $<60$ Lux & 21 & 21,9 \\
2. & $\geq 60$ Lux & 75 & 78,1 \\
\hline & Jumlah & 96 & 100,0 \\
\hline
\end{tabular}

Responden yang diteliti sebanyak 96 orang sebagian besar pencahayaan alaminya memenuhi syarat yaitu, 75 rumah $(78,1 \%)$ dan yang tidak memenuhi syarat yaitu 21 rumah $(21,9 \%)$.

Pencahayaan alami yang dimaksudkan dalam penelitian ini adalah pencahayaan alami dalam ruangan yang berasal dari sinar matahari. Menurut Suyono (1995), bahwa pencahayaan alami ruangan yang memenuhi persyaratan kesehatan minimal intensitasnya lebih dari 60 lux dan tidak menyilaukan. Ruangan rumah yang tidak memiliki pencahayaan yang cukup akan merangsang pertumbuhan kuman termasuk kuman Micobakterium Tuberculose penyebab penyakit TB. Paru. Pencahayaan langsung dalam ruangan dapat mengurangi terjadinya penularan TB. Paru, karena cahaya ultraviolet dari sinar matahari yang masuk kedalam ruangan dapat membunuh kuman Mycobacterium Tubrculose. Cahaya matahari mempunyai daya untuk membunuh bakteri.
Cahaya matahari masuk ke dalam ruangan rumah minimal 60 lux .

Responden dengan pencahayaan alami yang memenuhi syarat memiliki akses masuknya cahaya matahari lebih baik. Pencahayaan tersebut dapat masuknya cahaya matahari lebih baik. Pencahayaan tersebut dapat masuk melalui lubang ventilasi, jendela maupun pintu yang sering dibuka, atau dapat melalui genteng kaca. Responden dengan pencahayaan alami tidak memenuhi syarat yang dikarenakan kurangnya akses untuk masuknya cahaya ke dalam ruangan rumah akibat lubang ventilasi dan jendela yang jarang dibuka. Selain itu beberapa rumah responden jalan masuk cahaya terhalang oleh rumah warga di sampingnya, karena kondisi rumah yang berdempetan antara satu rumah dengan rumah yang lain.

Pencahayaan alami yang masuk ke dalam rumah penting bagi upaya pencegahan $\mathrm{Tb}$ paru. Oleh karena itu, keluarga mengupayakan agar pencahayaan alami dapat masuk ke dalam rumah dengan membuka jendela dan korden yang menutup kaca..

\section{Kepadatan hunian rumah responden}

Kepadatan hunian rumah responden di wilayah Puskesmas II Ajibarang dapat dilihat pada tabel 4 dibawah ini:

Tabel. 4. Distribusi Frekuensi Kondisi Kepadatan Hunian Rumah

\begin{tabular}{cccc}
\hline No & $\begin{array}{c}\text { Kepadatan } \\
\text { hunian }\end{array}$ & $\begin{array}{c}\text { Frekuensi } \\
\text { (Orang) }\end{array}$ & $\begin{array}{c}\text { Persentase } \\
(\%)\end{array}$ \\
\hline 1. & $<10 \mathrm{~m}^{2}$ & 20 & 20,8 \\
2. & $\geq 10 \mathrm{~m}^{2}$ & 76 & 79,2 \\
\hline & Jumlah & 96 & 100,0 \\
\hline
\end{tabular}

Responden yang diteliti sebanyak 96 orang sebagian besar kepadatan huniannya memenuhi syarat, yaitu 76 rumah $(79,2 \%)$ dan yang tidak memenuhi syarat yaitu 20 rumah $(20,8 \%)$.

Kepadatan hunian rumah akan meningkatkan suhu ruangan yang disebabkan oleh pengeluaran panas badan yang akan meningkatkan kelembaban akibat uap air dari pernapasan tersebut. Kurangnya pengetahuan dan biaya untuk membangun rumah sehat dapat menyebabkan kepadatan hunian, selain 
faktor budaya warga dayak yang dalam satu rumah biasa dihuni lebih dari 2 Kepala Keluarga (KK).

Kepadatan hunian ruang tidur merupakan perbandingan antara luas ruang tidur dengan jumlah individu semua umur yang menempati ruang tidur tersebut (Soedjajadi Keman, 2005). Semakin banyaknya penghuni, maka kadar oksigen bebas dalam ruangan menurun $(0,04 \%)$ sehingga daya tahan tubuh penghuninya menurun, ruangan yang sempit akan membuat nafas sesak dan mudah tertular penyakit dari anggota keluarga lain (Suyono, 1985).

Anggota keluarga yang sudah dewasa dan akan menikah hendaknya mempertimbangkan untuk tempat tinggalnya, sehingga tidak menambah kepadatan hunian rumah dengan adanya anggota keluarga yang baru. Keluarga yang masih tinggal bersama orang tua hendaknya merencanakan agar dapat memiliki rumah sendiri sehingga kepadatan hunian rumah dapat memenuhi persyaratan kesehatan.

\section{B. Analisis Bivariat}

Analisis bivariat dilakukan untuk menganalisis hubungan kondisi fisik rumah (jenis lantai, luas ventilasi rumah, pencahayaan alami dan kepadatan hunian) dengan kejadian TB paru menggunakan uji Chi Square yang hasilnya sebagai berikut.

1. Hubungan jenis lantai dengan kejadian TB paru

Hasil analisis jenis lantai dengan kejadian TB paru di wilayah Puskesmas II Ajibarang disajikan pada tabel berikut ini.

Tabel 5. Hubungan Jenis Lantai Rumah Dengan Kejadian Tb Paru di wilayah Puskesmas II Ajibarang Tahun 2016

\begin{tabular}{|c|c|c|c|c|c|c|c|}
\hline \multirow{2}{*}{ Jenis Lantai } & \multicolumn{2}{|c|}{ Kelompok } & \multirow{2}{*}{ Total } & \multirow{2}{*}{$\mathrm{P}$} & \multirow{2}{*}{ OR } & \multicolumn{2}{|c|}{ CI $95 \%$} \\
\hline & Kasus & Kontrol & & & & Lower & Upper \\
\hline Tidak Kedap & $\begin{array}{c}22 \\
667 \%\end{array}$ & $\begin{array}{c}11 \\
333 \%\end{array}$ & $\begin{array}{c}38 \\
100 \%\end{array}$ & & & & \\
\hline air & $66,7 \%$ & $33,3 \%$ & $100,0 \%$ & & & & \\
\hline Kedap Air & $\begin{array}{c}26 \\
41,3 \% \\
\end{array}$ & $\begin{array}{c}37 \\
58,7 \% \\
\end{array}$ & $\begin{array}{c}63 \\
65,6 \% \\
\end{array}$ & 0,018 & 2,846 & 1,180 & 6,866 \\
\hline Total & $\begin{array}{c}48 \\
50,0 \%\end{array}$ & $\begin{array}{c}48 \\
50,0 \%\end{array}$ & $\begin{array}{c}96 \\
100,0 \%\end{array}$ & & & & \\
\hline
\end{tabular}

Tabel 5 menunjukkan bahwa dari 38 rumah dengan jenis lantai tidak kedap air, sebagian besar terdapat penderita TB paru $(66,7 \%)$. Dari 63 rumah dengan jenis lantai kedap air, sebagian besar tidak terdapat penderita TB paru $(58,7 \%)$.

Hasil pengujian chi-square menunjukkan $p$-value sebesar 0,018 yang lebih kecil dari $\alpha$ $(0,018<0,05)$ maka disimpulkan terdapat hubungan yang signifikan antara jenis lantai dengan kejadian TB Paru. Hasil perhitungan OR menunjukkan angka 2,846 artinya orang yang tinggal di rumah dengan jenis lantai tidak kedap air memiliki risiko menderita TB Paru 2,846 kali lebih besar dibandingkan orang yang tinggal di rumah dengan jenis lantai kedap air.

Terjadinya hubungan jenis lantai rumah terhadap penyakit TB.Paru diwilayah
Puskesmas II Ajibarang, karena sebagian besar lantai yang dipergunakn oleh penderita TB. Paru dalam keadaan lembab, kotor dan berdebu. Sehingga kondisi tersebut perlu segera ditangani supaya tidak membahayakan bagi kesehatan. Beberapa upaya yang dapat dilakukan antara lain adalah dengan meningkatkan kegiatan penyehatan perumahan melalui kegiatan pembinaan rumah sehat dan pemugaran perumahan dan lingkungan desa terpadu ( P2LDT).

Hasil penelitian ini sejalan dengan penelitian Greis (2015) yang menunjukkan ada hubungan yang signifikan antara jenis lantai dengan kejadian TB Paru ( $p$ value $=0,000$ dan OR 21,000).

Jenis lantai yang tidak kedap air dapat menjadi sumber bibit penyakit atau berkembangbiaknya kuman penyebab $\mathrm{Tb}$ 
paru. Kuman penyebab $\mathrm{Tb}$ paru dapat berterbangan karena terbawa angin yang dapat terhirup oleh orang sehat dan pada gilirannya akan terinfeksi kuman Tb paru.
2. Hubungan luas ventilasi rumah dengan Kejadian TB Paru

Hasil analisis luas vantilasi dengan kejadian TB paru di wilayah Puskesmas II Ajibarang disajikan pada tabel berikut ini.

Tabel 6. Hubungan luas ventilasi rumah dengan Kejadian TB Paru di wilayah Puskesmas II Ajibarang Tahun 2016

\begin{tabular}{|c|c|c|c|c|c|c|c|}
\hline \multirow{2}{*}{$\begin{array}{c}\text { Luas } \\
\text { Ventilasi }\end{array}$} & \multicolumn{2}{|c|}{ Kelompok } & \multirow{2}{*}{ Total } & \multirow{2}{*}{$\mathrm{P}$} & \multirow{2}{*}{ OR } & \multicolumn{2}{|c|}{ CI $95 \%$} \\
\hline & Kasus & Kontrol & & & & Lower & Upper \\
\hline$<10 \% \mathrm{dr}$ & 26 & 15 & 41 & & & & \\
\hline luas lantai & $63,4 \%$ & $36,6 \%$ & $100,0 \%$ & & & & \\
\hline $\begin{array}{l}\geq 10 \% \mathrm{dr} \\
\text { luas lantai }\end{array}$ & $\begin{array}{c}22 \\
40,0 \%\end{array}$ & $\begin{array}{c}33 \\
60,0 \%\end{array}$ & $\begin{array}{c}55 \\
100,0 \%\end{array}$ & 0,023 & 2,600 & 1,130 & 5,984 \\
\hline Total & $\begin{array}{c}48 \\
50,0 \%\end{array}$ & $\begin{array}{c}48 \\
50,0 \%\end{array}$ & $\begin{array}{c}96 \\
100,0 \%\end{array}$ & & & & \\
\hline
\end{tabular}

Tabel 6 menunjukkan bahwa dari 41 rumah dengan luas ventilasi tidak memenuhi syarat, sebagian besar terdapat penderita $\mathrm{TB}$ paru $(63,4 \%)$. Dari 55 rumah dengan luas ventilasi memenuhi syarat, sebagian besar tidak terdapat penderita TB paru $(60,0 \%)$.

Hasil pengujian chi-square menunjukkan $p$-value sebesar 0,023 yang lebih kecil dari $\alpha$ $(0,023<0,05)$ maka disimpulkan terdapat hubungan yang signifikan antara luas ventilasi dengan kejadian TB Paru. Hasil perhitungan OR menunjukkan angka 2,600 artinya orang yang tinggal di rumah dengan luas ventilasi tidak memenuhi syarat memiliki risiko menderita TB Paru 2,846 kali lebih besar dibandingkan orang yang tinggal di rumah dengan luas ventilasi memenuhi syarat.

Ventilasi adalah usaha untuk memenuhi kondisi atmosfer yang menyenangkan dan menyehatkan manusia. Secara umum, penilaian ventilasi rumah dengan cara membandingkan antara luas ventilasi dan luas lantai rumah, dengan menggunakan Rolemeter. Secara umum menurut Kepmenkes RI No. 829/Menkes/SK/ VII/1999 luas ventilasi yang memenuhi syarat $10-20 \%$ dari luas lantai.

Ventilasi bermanfaat bagi sirkulasi pergantian udara dalam rumah serta mengurangi kelembaban di dalam ruangan. Salah satunya yang mempengaruhi kelembaban adalah keringat manusia, semakin banyak manusia dalam satu ruangan maka semakin tinggi kelembaban ruangan tersebut. Ventilasi mempengaruhi proses dilusi udara, juga dengan kata lain mengencerkan konsentrasi kuman tuberkulosis dan kuman lain, terbawa keluar dan mati terkena sinar ultraviolet (Achmadi, 2010).

Hasil penelitian ini sejalan dengan penelitian Mawardi (2014) yang menunjukkan ada hubungan yang signifikan antara luas ventilasi dengan kejadian TB Paru ( $p$ value $=$ 0,003 dan OR 6,5).

Ventilasi yang sudah memenuhi syarat akan menjadi jalan masuknya udara dan sinar matahari yang dapat membunuh kuman $\mathrm{Tb}$ paru. Selain itu, sinar yang masuk juga akan mempengaruhi kelembaban dalam rumah yang dapat mendukung berkembangbiaknya kuman Tb paru.

3. Hubungan Pencahayaan Alami Dengan Kejadian TB Paru

Hasil analisis pencahayaan alami dengan kejadian TB paru di wilayah Puskesmas II Ajibarang disajikan pada tabel berikut ini. 
Tabel 7. Hubungan Pencahayaan Alami Dengan Kejadian TB Paru di wilayah Puskesmas II Ajibarang Tahun 2016

\begin{tabular}{|c|c|c|c|c|c|c|c|}
\hline \multirow{2}{*}{$\begin{array}{c}\text { Pencahayaan } \\
\text { alami }\end{array}$} & \multicolumn{2}{|c|}{ Kelompok } & \multirow{2}{*}{ Total } & \multirow{2}{*}{$\mathrm{P}$} & \multirow{2}{*}{ OR } & \multicolumn{2}{|c|}{ CI 95\% } \\
\hline & Kasus & Kontrol & & & & Lower & Upper \\
\hline$<60 \mathrm{llu}$ & 15 & 6 & 21 & & & & \\
\hline$<0010 x$ & $71,4 \%$ & $28,6 \%$ & $100,0 \%$ & & & & \\
\hline$\geq 60 \operatorname{lux}$ & $\begin{array}{c}33 \\
44,0 \%\end{array}$ & $\begin{array}{c}42 \\
56,0 \%\end{array}$ & $\begin{array}{c}75 \\
100,0 \%\end{array}$ & 0,026 & 3,182 & 1,113 & 9,100 \\
\hline Total & $\begin{array}{c}48 \\
50,0 \%\end{array}$ & $\begin{array}{c}48 \\
50,0 \%\end{array}$ & $\begin{array}{c}96 \\
100,0 \%\end{array}$ & & & & \\
\hline
\end{tabular}

Tabel 7 menunjukkan bahwa dari 21 rumah dengan pencahayaan alami tidak memenuhi syarat, sebagian besar terdapat penderita TB paru $(71,4 \%)$. Dari 75 rumah dengan pencahayaan alami memenuhi syarat, sebagian besar tidak terdapat penderita $\mathrm{TB}$ paru $(56,0 \%)$.

Hasil uji chi-square menunjukkan $p$ value $=0,026$ yang lebih kecil dari $\alpha(0,026<$ $0,05)$ maka disimpulkan terdapat hubungan yang signifikan antara pencahayaan alami dengan kejadian TB Paru. Hasil perhitungan OR menunjukkan angka 3,182 artinya orang yang tinggal di rumah dengan pencahayaan alami tidak memenuhi syarat memiliki risiko menderita TB Paru 3,182 kali lebih besar dibandingkan orang yang tinggal di rumah dengan pencahayaan alami memenuhi syarat.

Rumah sehat memerlukan cahaya yang cukup khususnya cahaya alami berupa cahaya matahari (UV). Pencahayaan alami ruangan rumah adalah penerangan yang bersumber dari sinar matahari yaitu semua jalan yang memungkinkan untuk masuknya cahaya matahari alamiah, misalnya jendela atau genting kaca. Cahaya ini sangat penting, karena dapat membunuh bakteribakteri patogen di dalam rumah (Notoatmodjo, 2011).

Upaya penanganan yang perlu dilakukan adalah dengan meningkatkan pengetahuan responden, pemberian stimulan jendela dan

Tabel 8. Hubungan Kepadatan Hunian Dengan Kejadian TB Paru di wilayah Puskesmas II Ajibarang Tahun 2016

\begin{tabular}{|c|c|c|c|c|c|c|c|}
\hline \multirow{2}{*}{$\begin{array}{c}\text { Kepadatan } \\
\text { Hunian }\end{array}$} & \multicolumn{2}{|c|}{ Kelompok } & \multirow{2}{*}{ Total } & \multirow{2}{*}{$\mathrm{P}$} & \multirow{2}{*}{ OR } & \multicolumn{2}{|c|}{ CI 95\% } \\
\hline & Kasus & Kontrol & & & & Lower & Upper \\
\hline & 16 & 4 & 20 & & & & \\
\hline$\leq 10 \mathrm{~m}^{2}$ & $60,0 \%$ & $40,0 \%$ & $100,0 \%$ & & & & \\
\hline$>10 \mathrm{~m}^{2}$ & $\begin{array}{c}32 \\
42,1 \%\end{array}$ & $\begin{array}{c}44 \\
57,9 \%\end{array}$ & $\begin{array}{c}76 \\
100,0 \%\end{array}$ & 0,003 & 5,500 & 1,679 & 18,016 \\
\hline Total & $\begin{array}{c}48 \\
50,0 \%\end{array}$ & $\begin{array}{c}48 \\
50,0 \%\end{array}$ & $\begin{array}{c}96 \\
100,0 \%\end{array}$ & & & & \\
\hline
\end{tabular}

pemberian genting kaca kepada masyarakat atau responden TB. Paru.

Hasil penelitian ini sejalan dengan penelitian Amalia (2015) yang menunjukkan ada hubungan yang signifikan antara pencahayaan dengan kejadian TB Paru ( $p$ value $=0,003$ dan OR 8,125).

Terjadinya hubungan pencahayaan alami rumah terhadap penyakit TB.Paru di wilayah Puskesmas II Ajibarang, karena pencahayaan alami yang ada pada rumah penderita tidak memenuhi syarat. Hal tersebut disebabkan rumahnya saling berhimpitan, karena terhalang oleh tumbuhan, karena rumahnya tidak memiliki jendela dan tidak memiliki genting kaca, serta karena sengaja jendela tidak dibuka oleh pemiliknya, sehingga mengakibatkan cahaya alami yang masuk ke dalam ruangan berkurang. Berkurangnya cahaya alami yang masuk kedalam ruangan menyebabkan ruangan menjadi gelap dan lembab, sehingga dapat menimbulkan gangguan dan penyakit pada penghuninya.

\section{Hubungan Kepadatan Hunian Dengan Kejadian TB Paru}

Hasil analisis kepadatan hunian dengan kejadian TB paru di wilayah Puskesmas II Ajibarang disajikan pada tabel berikut ini. 
Tabel 8 menunjukkan bahwa dari 20 rumah dengan kepadatan hunian tidak memenuhi syarat, sebagian besar terdapat penderita TB paru (60,0\%). Dari 76 rumah dengan kepadatan hunian memenuhi syarat, sebagian besar tidak terdapat penderita TB paru $(57,9 \%)$.

Hasil pengujian chi-square menunjukkan $p$-value sebesar 0,003 yang lebih kecil dari $\alpha$ $(0,003<0,05)$ maka disimpulkan terdapat hubungan yang signifikan antara pencahayaan alami dengan kejadian TB Paru. Hasil perhitungan OR menunjukkan angka 5,500 artinya orang yang tinggal di rumah dengan kepadatan hunian tidak memenuhi syarat memiliki risiko menderita TB Paru 5,500 kali lebih besar dibandingkan orang yang tinggal di rumah dengan kepadatan hunian memenuhi syarat.

Kepadatan hunian akan memudahkan terjadinya penularan penyakit TB paru di dalam rumah tangga. Bila dalam satu rumah terdapat satu orang penderita TB paru aktif dan tidak diobati secara benar akan menginfeksi anggota keluarga lain terutama kelompok yang rentan seperti balita. Semakin padat huni suatu rumah maka semakin besar risiko penularan TB paru.

Hasil penelitian ini sejalan dengan penelitian Mawardi (2014) yang menunjukkan ada hubungan yang signifikan antara luas ventilasi dengan kejadian TB Paru ( $p$ value $=$ 0,006 dan OR 6,2).

Terjadinya hubungan kepadatan hunian rumah terhadap penyakit TB.Paru di wilayah Puskesmas II Ajibarang, karena kondisi rumahnya sempit, jumlah penghuninya besar, kondisi lingkungan kelurga yang masih menghendaki untuk bersatu dan berkumpul bersama dalam satu keluarga atau satu rumah serta karena kemampuan dari keluarga tersebut yang tidak mampu membuatkan rumah bagi keluarganya yang telah berumah tangga. Kondisi tersebut merupakan faktor risiko yang dapat memicu timbulnya suatu penyakit, termasuk didalamnya adalah penyakit TB. Paru. Karena itu perlu upaya penanganan. Beberapa upaya yang dapat dilakukan antara lain adalah dengan meningkatkan pengetahuan dan sikap kemandirian pada masyarakat.

\section{KESIMPULAN DAN SARAN}

\section{A. Kesimpulan}

1. Jenis lantai rumah sebagian besar kedap air yaitu 63 rumah $(65,6 \%)$, luas ventilasi memenuhi syarat yaitu 55 rumah $(57,3 \%)$, pencahayaan alami memenuhi syarat yaitu 75 rumah $(78,1 \%)$ dan kepadatan huniannya memenuhi syarat yaitu 76 rumah $(79,2 \%)$.

2. Ada hubungan antara jenis lantai dengan kejadian TB Paru di Wilayah Puskesmas II Ajibarang Tahun 2015 ( $\mathrm{p}$ value = 0,018; $\mathrm{OR}=2,846$ ).

3. Ada hubungan antara luas ventilasi dengan kejadian TB Paru di Wilayah Puskesmas II Ajibarang Tahun 2015 ( $\mathrm{p}$ value $=0,023$; $\mathrm{OR}=2,600$ ).

4. Ada hubungan antara pencahayaan alami dengan kejadian TB Paru di Wilayah Puskesmas II Ajibarang Tahun 2015 (p value $=0,026 ; \mathrm{OR}=3,182$ ).

5. Ada hubungan antara kepadatan hunian dengan kejadian TB Paru di Wilayah Puskesmas II Ajibarang Tahun 2015 (p value $=0,003 ; \mathrm{OR}=5,500$ ).

\section{B. Saran}

1. Bagi Institusi Pendidikan

Hasil penelitian ini perlu dipublikasikan agar dapat dijadikan referensi ilmiah bagi peneliti yang tertarik meneliti tentang faktor yang dapat berhubungan dengan kejadian TB paru.

2. Bagi Pemerintah

Hasil penelitian dapat dimanfaatkan sebagai masukan dan informasi tentang program penanggulangan TB paru.

3. Bagi Peneliti

Penelitian ini perlu dikembangkan lebih lanjut dengan meneliti faktor lain yang dapat mempengaruhi kejadian TB paru dari aspek perilaku keluarga penderita TB paru.

4. Bagi Masyarakat

Masyarakat, khususnya yang memiliki anggota keluarga penderita $\mathrm{Tb}$ paru agar dapat melakukan pencegahan terhadap penularan $\mathrm{Tb}$ paru pada anggota keluarga lainnya dengan membiasakan 
membuka jendela rumah di pagi hari dan menutupnya di sore hari. Kondisi fisik rumah yang sudah memenuhi syarat, tetapi tidak dirawat dan difungsikan dengan baik belum mendukung upaya pencegahan $\mathrm{Tb}$ paru.

\section{Daftar Pustaka}

Achmadi, U.F., 2010. Manajemen Penyakit Berbasis Wilayah. Jakarta.Universitas Indonesia-Press.

Amin, Muhamad / Hood Alsagaff, 1989, Pengantar Ilmu Penyakit Paru, Surabaya. Air Langga Univ.Press

Annies, 2006. Manajemen Berbasis Lingkungan; Solusi Mencegah dan Menanggulangi Penyakit Menular. Jakarta, Elex Media Komputindo,

Arikunto.S, 2002, Prosedur Penelitian Suatu Pendekatan Praktek, Jakarta. Rineka Cipta.

Bahar, Asril , 1990, Ilmu Penyakit Dalam, Tuberkulosis Paru, Jakarta. Balai Penerbit FKUI

Bastaman Basuki, 2001, Aplikasi metode kasus kontrol, Kedokteran Komunikasi, Jakarta.Fakultas Kedokteran. UI Press.

Departemen Kesehatan RI., 2008, Pedoman Nasional Penanggulangan Tubeculosis, Jakarta. Departemen Kesehatan RI.

2002 , Pedoman Nasional Penanggulangan Tuberkolosis, Jakarta : Departemen Kesehatan RI.

2001 ,

Pedoman Nasional Penanggulangan Tuberkolosis, Jakarta : Departemen Kesehatan RI.

1999

Keputusan Menteri Kesehatan RI No. 829 / Menkes / SK / VII / 1999, tentang Persyaratan Kesehatan Perumahan, Jakarta.

Departemen Pekerjaan Umum, 1986, Pedoman Teknik Pembangunan Perumahan Sederhana Tidak bersusun, Jakarta : SK. Menteri Pekerjaan Umum No. 20/Kep/1986,
Dinas Kesehatan Propinsi Jawa Tengah, 2005, Pedoman Tenis Penilaian Rumah Sehat untuk Puskesmas, Semarang.

Dinas Kesehatan Propinsi Jawa Tengah, 2000. Faktor Risiko yang Mempengaruhi Kesembuhan Pengobatan Penderita TB Paru di Jawa Tengah Tahun 2000, Laporan Hasil Penelitian (Tahap II), Dinkes Prop. Jawa Tengah, Semarang.

Djasio Sanropie, dkk, 1989, Pengawasan Penyehatan Pemukiman untuk Institusi Pendidikan Sanitasi Lingkungan, Jakarta. Pusdiknakes Depkes RI.

Ikeu Nurhidayah, 2007, Hubungan antara karakteristik lingkungan rumah dengan kejadian TB. Anak di Kecamatan Paseh Kabupaten Sumedang. Bandung . Univversitas Padjajaran, Fakultas Ilmu Keperawatan Bandung.

John Crofton, Norman Horne, Fred Miller: 2002, Tuberkulosis klinis, Alih Bahasa, Muherman Harun, Jakarta : Widya Medika.

Kumar, 2000, “Apa itu TB ?” www.ngo.or.id

Marsum, 2005, Hubungan sanitasi rumah dengan kejadian TB.Paru di wilayah kerja Puskesmas Bulu Pesanteren Kabupaten kebumen Tahun 2005, Buletin Keslingmas No. 87-88 Tahun XXV Triwulan III dan IV Juli Desember 2005.

Misnadiarly, Simanjuntak, CH., Pudjarwoto, 1990, Pengaruh Faktor gizi dan Pemberian BCG Terhadap Timbulnya Penyakit Tuberkulosis Paru, Cermin Dunia Kedokteran, 63 : 20 -24

Noor, Nur Nasry, 1994, Pengantar Epidemologi Penyakit Menular, Jakarta : Rineka Cipta

Notoatmodjo.S, 2003, Ilmu Kesehatan Masyarakat. Jakarta. Rineka Cipta.

Notoatmodjo. S. 2011. Kesehatan Masyarakat Ilmu dan Seni. Jakarta: Rineka Cipta

Reksosoebroto, Soebagio, 1978, Hygiene dan Sanitasi, Jakarta :APK-TS

Soemirat, Juli, 2000, Epidemiologi Lingkungan, Yogyakarta: Gajah Mada Univ. Press.

Suyono, 1985, Pokok Bahasan Modul Perumahan dan Pemukiman, Jakarta: Pusdiknakes 